\section{Cureus}

Received 06/21/2019

Review began 06/25/2019

Review ended 06/25/2019

Published 07/02/2019

\section{(c) Copyright 2019}

Parajuli et al. This is an open access article distributed under the terms of the Creative Commons Attribution License CC-BY 3.0., which permits unrestricted use, distribution, and reproduction in any medium, provided the original author and source are credited.

\title{
Trimethoprim-sulfamethoxazole Induced Pancytopenia: A Common Occurrence but A Rare Diagnosis
}

Priyanka Parajuli ${ }^{1}$, Abdisamad M. Ibrahim ${ }^{1}$, Harris H. Siddiqui ${ }^{2}$, Odalys Estefania Lara Garcia 1 , Manjari R. Regmi ${ }^{1}$

1. Internal Medicine, Southern Illinois University School of Medicine, Springfield, USA 2. Internal Medicine, Southern Illinois University School of Medicine, Springfield , USA

$\square$ Corresponding author: Priyanka Parajuli, priyankaparajulimd@gmail.com Disclosures can be found in Additional Information at the end of the article

\section{Abstract}

Trimethoprim-sulfamethoxazole (TMP-SMX) is a bacteriostatic antimicrobial medication used for the treatment of a variety of infections and has many reported skin and hematologic side effects. Due to the easy availability and cost effectiveness, TMP-SMX is one of the medications commonly used for treatment of skin and soft tissue in patients with methicillin-resistant Staphylococcus aureus (MRSA) infection. One of the rare hematologic manifestations of TMPSMX is pancytopenia, which is a reduction in all cell lines. In this case report, we are documenting a case of pancytopenia due to severe drug reaction to TMP-SMX in a 70-year-old female after two weeks of medication use. Upon initial stabilization she underwent a thorough workup and was subsequently diagnosed with severe drug-induced pancytopenia. Detailed history, early diagnosis, prompt discontinuation of the offending medication along with supportive care remain the mainstay of treatment in the management of TMP-SMX induced pancytopenia.

Categories: Internal Medicine, Infectious Disease, Other

Keywords: pancytopenia, bactrim, trimethoprim sulfamethoxazole, tmp-smx, mrsa

\section{Introduction}

Pancytopenia is the reduction in all blood cell lines. A reduced production of the cell lines, intrinsic, or an increased destruction of the cell lines, extrinsic, can cause pancytopenia [1]. Pancytopenia can insidiously develop over a period. Alternatively, it can be of acute onset and progress quickly to disseminated intravascular coagulation, rapid hemolysis, and fulminant sepsis [2]. The differential diagnosis for a patient with pancytopenia is broad and the etiology can range from deficiency in nutrients such as folate and vitamin B12, use of antibiotics, and chemotherapeutic agents to transient viral marrow suppression and malignant bone marrow infiltration [3]. Drug-induced pancytopenia is an intrinsic cause of pancytopenia and is mostly considered a diagnosis of exclusion [1]. In this case report, we will discuss a case of a patient with drug-induced pancytopenia along with the differential diagnosis for pancytopenia of unknown origin and expected finding in each pathology.

\section{Case Presentation}

A 70-year-old female presented to the ED with complaints of hematemesis, hemoptysis, melenic stools, and diffuse generalized body pain for four days. She denied any fevers, chills, lightheadedness, dizziness, chest pain, shortness of breath, or abdominal pain. There was no 


\section{Cureus}

history of inflammatory bowel disease or gastric ulcers. On physical examination, she was in mild distress, hypotensive, tachycardic, and breathing room air. She had multiple ulcers throughout her hard palate, soft palate, and lips. Her abdomen was soft and nondistended with normal bowel sounds. After initial stabilization, she was admitted for further evaluation and management. CT scan of the chest, abdomen, and pelvis did not reveal any acute findings. Admission lab work is demonstrated below in Table 1 . 


\section{Cureus}

\begin{tabular}{|c|c|c|}
\hline Lab parameter & Values & Reference range \\
\hline $\mathrm{Hgb}$ & $7.5 \mathrm{~g} / \mathrm{dL}$ & $12.0-16.0 \mathrm{gm} / \mathrm{dL}$ \\
\hline MCV & $77.0 \mathrm{fL}$ & $81-94 \mathrm{fL}$ \\
\hline WBC & $0.7 \mathrm{~K} / \mathrm{CUMM}$ & 3.4-9.4 K/CUMM \\
\hline PIt & $9.0 \mathrm{~K} / \mathrm{CUMM}$ & $140-410 \mathrm{~K} / \mathrm{CUMM}$ \\
\hline ANC & $0.1 \mathrm{~K} / \mathrm{CUMM}$ & 1.5-6.5 K/CUMM \\
\hline Absolute reticulocyte count & $0.1 \%$ & $0.5 \%-0.2 \%$ \\
\hline Absolute lymphocyte count & $0.5 \mathrm{~K} / \mathrm{CUMM}$ & 0.9-3.0 K/CUMM \\
\hline PT & $14.1 \mathrm{~s}$ & $11.9-14.9 \mathrm{~s}$ \\
\hline INR & 1.1 & $0.9-1.1$ \\
\hline PTT & $26.0 \mathrm{~s}$ & $22.9-35.1 \mathrm{~s}$ \\
\hline AST & $16 \mathrm{IU} / \mathrm{L}$ & 13-39 IU/L \\
\hline ALT & $11 \mathrm{IU} / \mathrm{L}$ & 7-54 IU/L \\
\hline LDH & 112 IU/L & 140-271 IU/L \\
\hline Fibrinogen & $756 \mathrm{mg} / \mathrm{dL}$ & $200-400 \mathrm{mg} / \mathrm{dL}$ \\
\hline Fibrin split products & $20 \mathrm{uG} / \mathrm{mL}$ & $0-9 \mathrm{uG} / \mathrm{mL}$ \\
\hline D-dimer & $1.18 \mathrm{mcg} / \mathrm{mL}$ & $0.27-0.50 \mathrm{mcg} / \mathrm{mL}$ \\
\hline Total bilirubin & $0.7 \mathrm{mg} / \mathrm{dL}$ & $0.3-1.0 \mathrm{mg} / \mathrm{dL}$ \\
\hline Direct bilirubin & $0.2 \mathrm{mg} / \mathrm{dL}$ & $0.0-0.2 \mathrm{mg} / \mathrm{dL}$ \\
\hline Vitamin B12 & $273 \mathrm{pg} / \mathrm{mL}$ & $>=200 \mathrm{pg} / \mathrm{mL}$ \\
\hline Folate & $7.5 \mathrm{ng} / \mathrm{mL}$ & $>=6.0 \mathrm{ng} / \mathrm{mL}$ \\
\hline Peripheral smear & \multicolumn{2}{|c|}{ Marked pancytopenia. No blasts, spherocytes, or schistocytes } \\
\hline Direct Coombs test & \multicolumn{2}{|l|}{ Negative } \\
\hline SPEP and UPEP & \multicolumn{2}{|c|}{ No abnormal bands } \\
\hline Hepatitis B, C, HIV, CMV, and EBV serologies & Negative & \\
\hline
\end{tabular}

\section{TABLE 1: Laboratory data.}

Hgb, hemoglobin; MCV, mean corpuscular volume; WBC, white blood cell; PIt, platelet; ANC, absolute neutrophil count; PT, prothrombin time; INR, international normalized ratio; PTT, partial thromboplastin time; AST, aspartate aminotransferase; ALT, alanine aminotransferase; LDH, lactate dehydrogenase; SPEP, serum protein electrophoresis; UPEP, urine protein electrophoresis; HIV, human immunodeficiency virus; CMV, cytomegalovirus; EBV, Epstein-Barr virus. 
Two weeks prior to admission her hemoglobin was slightly decreased at $11.0 \mathrm{~g} / \mathrm{dL}$. Her WBC count and platelet count were both within normal limits. The only new medication patient took from the time of onset of her symptoms leading to her admission was TMP-SMX for right lower extremity cellulitis. Over the course of her admission, her TMP-SMX was stopped and she was transfused two units of platelets and three units of packed RBCs. She was also treated with recombinant human granulocyte colony-stimulating factor (rhG-CSF). At a follow-up visit two months later, the patient's complete blood count (CBC) had normalized.

\section{Discussion}

According to the Infectious Diseases Society of America (IDSA) guidelines, routine treatment for community-acquired MRSA in patients presenting with purulent cellulitis is TMP-SMX [4]. It is a sulfonamide drug and is a combination of two antimicrobial agents that work sequentially to inhibit enzyme systems involved in the bacterial synthesis of tetrahydrofolic acid (THF). Reduced availability of THF inhibits thymidine synthesis, which in turn inhibits DNA synthesis [5-6]. The more common adverse reactions to TMP-SMX involve gastrointestinal tract (nausea, vomiting) and skin (rash and pruritus) [7]. However, a few life-threatening side effects such as pancytopenia, Steven-Johnson syndrome, hepatitis, and renal tubular acidosis have also been reported [7]. Blood dyscrasias as a result of TMP-SMX use was reported at 1 in 18,000 in a Swedish population study [8]. A population-based study in Seattle, Washington area concluded low hospitalization rate for blood disorder secondary to use of TMP-SMX [9].

Pancytopenia is a known side effect of TMP-SMX; however, it has not attracted much attention in the past few years and it is reflected by the sparsity of publications. The likely causes of pancytopenia are influenced by geography, socioeconomic conditions, and endemic illnesses [2]. The vast majority of pancytopenia in adults is caused by acquired disorders, such as infections, nutritional deficiencies, medications, and cancers [3].

In our report, the patient was started on TMP-SMX to cover MRSA for purulent cellulitis of her right lower leg. Initially, the patient tolerated TMP-SMX well with no side effects. However, after two weeks of treatment, she presented to the ED with hematemesis and coffee-ground emesis. She was diagnosed with drug-induced pancytopenia after ruling out disseminated intravascular coagulation (DIC), thrombotic thrombocytopenic purpura (TTP), nutritional deficiency, viral etiology, possible autoimmune disorder, and sepsis. In the following figures, we have summarized the diagnostic approach for patients presenting with pancytopenia of unknown etiology and unique features of each differential diagnosis as

Figures 1-2, respectively. 


\section{Cureus}

Pancytopenia of Unknown Etiology

-Liver function test,

Coagulation profile

Peripheral blood smear and Reticulocyte count

-Vitamin B12, Folate level

Viral Serology ( EBV, HBV,

HCV, CMV, HIV)

-Autoimmnune Profile

Bone marrow aspiration

Biopsy

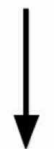

Bone marrow cytogenetics and Immunophenotyping

\section{FIGURE 1: Diagnostic approach for patients presenting with pancytopenia of unknown etiology.}

HIV, human immunodeficiency virus; CMV, cytomegalovirus; EBV, Epstein-Barr virus; HBV, hepatitis $B$ virus; $\mathrm{HCV}$, hepatitis $\mathrm{C}$ virus.

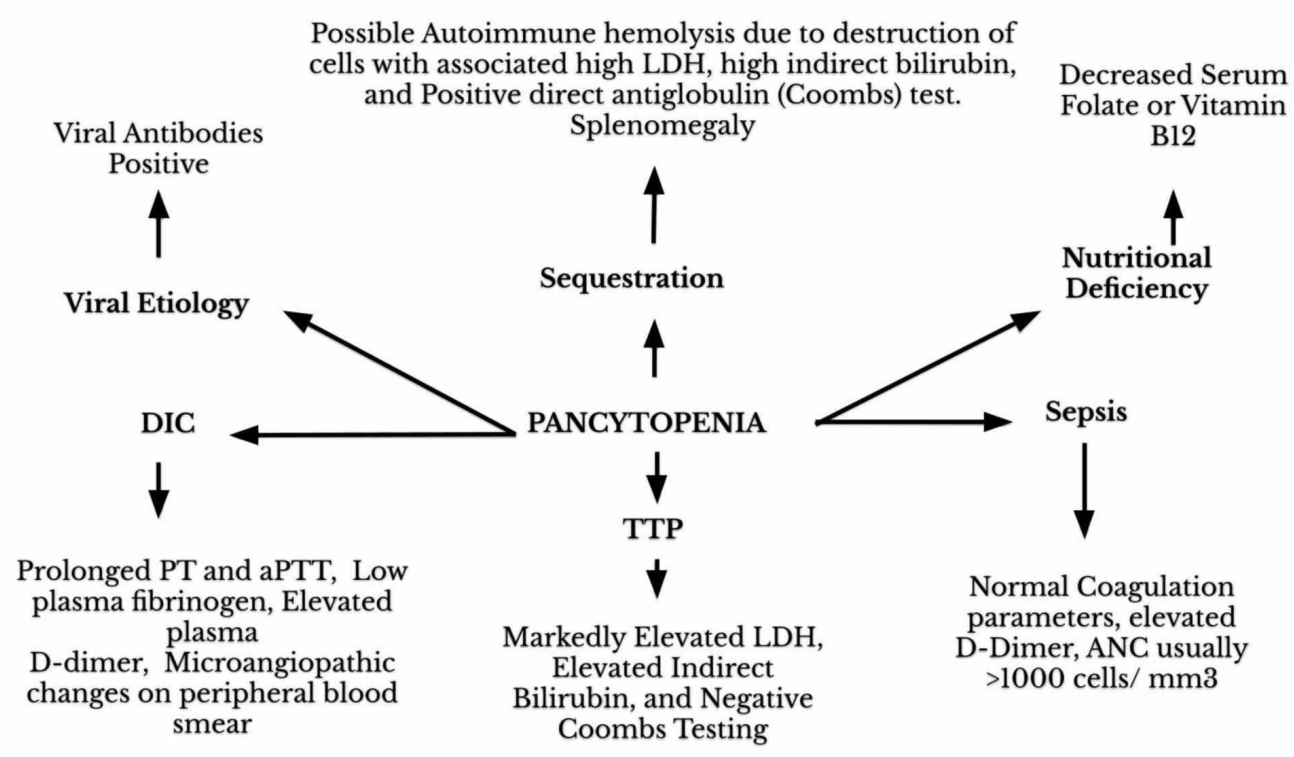

\section{FIGURE 2: Differential diagnoses and expected findings in} pancytopenia of various etiologies.

LDH, lactate dehydrogenase; TTP, thrombotic thrombocytopenic purpura; aPTT, activated partial thromboplastin time; ANC, absolute neutrophil count. 


\section{Conclusions}

The differential diagnoses in a patient with acute onset pancytopenia are very comprehensive. It is important to understand that TMP-SMX can cause an idiosyncratic allergic reaction leading to pancytopenia. However, due to inadequate reports regarding such reaction drugrelated pancytopenia is not a leading differential diagnosis and can affect the management of patients. Therefore, detailed history along with thorough physical examination and judicious laboratory investigation becomes extremely essential in investigating the cause of pancytopenia to initiate appropriate treatment.

\section{Additional Information}

\section{Disclosures}

Human subjects: Consent was obtained by all participants in this study. Conflicts of interest: In compliance with the ICMJE uniform disclosure form, all authors declare the following:

Payment/services info: All authors have declared that no financial support was received from any organization for the submitted work. Financial relationships: All authors have declared that they have no financial relationships at present or within the previous three years with any organizations that might have an interest in the submitted work. Other relationships: All authors have declared that there are no other relationships or activities that could appear to have influenced the submitted work.

\section{References}

1. Kelm DJ, Torres KM, Sohail MR: 46-year-old man with fevers, chills, and pancytopenia. Mayo Clin Proc. 2012, 87:799-802. 10.1016/j.mayocp.2012.03.012

2. Sharma R, Nalepa G: Evaluation and management of chronic pancytopenia . Pediatr Rev. 2016 , 37:101-113. 10.1542/pir.2014-0087

3. Crews J, Dawkins R: Acute-onset pancytopenia in a previously healthy teenager . J Paediatr Neonatal Dis. 2016, 1:105. 10.15744/2456-5482.1.105

4. Liu C, Bayer A, Cosgrove SE, et al.: Clinical practice guidelines by the Infectious Diseases Society of America for the treatment of methicillin-resistant Staphylococcus aureus infections in adults and children. Infect Dis. 2011, 52:e18-e55. 10.1093/cid/ciq146

5. Kalkut G: Sulfonamides and trimethoprim . Cancer Invest. 2009, 16:612-615. $10.3109 / 07357909809032892$

6. Gleckman R, Blagg N, Joubert DW: Trimethoprim: mechanisms of action, antimicrobial activity, bacterial resistance, pharmacokinetics, adverse reactions, and therapeutic indications. Pharmacotherapy. 1981, 1:14-19. 10.1002/j.1875-9114.1981.tb03548.x

7. Cunha BA: Antibiotic side effects. Med Clin North Am. 2001 , 85:149-285. 10.1016/S00257125(05)70309-6

8. Keisu M, Wiholm BE, Palmblad J: Trimethoprim-sulphamethoxazole-associated blood dyscrasias. Ten years' experience of the Swedish spontaneous reporting system. J Intern Med. 1990, 228:353-360. 10.1111/j.1365-2796.1990.tb00245.x

9. Myers MW, Jick H: Hospitalization for serious blood and skin disorders following cotrimoxazole. Br J Clin Pharmacol. 1997, 43:649-651. 10.1046/j.1365-2125.1997.00590.x 